\title{
Synthesis, Optical and Ferroelectric Properties of PZT Thin Films: A Experimental and Theoretical Investigation
}

\author{
D.S.L. Pontes, ${ }^{1,2}$ L. Gracia, ${ }^{1}$ F.M. Pontes, ${ }^{2}$ A. Beltrán ${ }^{1}$, J. Andrés ${ }^{1}$ and E. Longo ${ }^{3}$ \\ ${ }^{1}$ Departament de Química Física i Analítica, Universitat Jaume I, Campus de Riu Sec, \\ Castelló E-12080, Spain \\ ${ }^{2}$ Instituto de Química, UNESP CEP17033-360 Bauru, Brazil \\ ${ }^{3}$ LIEC, Instituto de Química, UNESP, P.O. Box 355, 14800-900, Araraquara, SP,
}

Brazil

\begin{abstract}
$\mathrm{PbZr}_{0.40} \mathrm{Ti}_{0.60} \mathrm{O}_{3}(\mathrm{PZT} 40 / 60)$ thin films with ferroelectric and dielectric properties have been grown on $\mathrm{Pt} / \mathrm{Ti} / \mathrm{SiO}_{2} / \mathrm{Si}$ and $\mathrm{LaAlO}_{3}$ (100) substrates using the chemical solution deposition method. These films have been characterized by different techniques such Xray diffraction (XRD), Raman, infrared and optical transmittance measurements. The transmittance curve of the PZT40/60 thin films on a $\mathrm{LaAlO}_{3}(100)$ substrate showed an optical band gap of 4.03 and $3.10 \mathrm{eV}$ for the direct and indirect transition processes, respectively. To complement experimental data, first principle calculations at the DFTB3LYP level were performed on periodic model systems of $\mathrm{PbTiO}_{3}$ and $\mathrm{PZT} 40 / 60$ to provide an insight into structural, optical and electronic behavior. The band gap of the PZT40/60 system for $\mathrm{PbO}$ and $\mathrm{ZrO}_{2}$ terminations is in agreement with trends of experimental data and results in smaller values than the band gap calculated for the $\mathrm{PbTiO}_{3}$ system.
\end{abstract}




\section{Introduction}

Hybrid materials based on oxide-supported films have attracted considerable attention because of their many practical applications. The control of the growth and properties of these hybrid structures is a major challenge in field and surface science strategies. Thin films of inorganic materials are used in diverse applications which are typically in polycrystalline form due to their relatively simple production. In recent years, there has been an increased interest in studies of perovskite $\mathrm{ABO}_{3}$ thin films due to remarkable achievements in the technology of ferroelectrics and their device applications $^{1,2}$ which do not exist in the individual bulk parent materials ${ }^{3-5}$; thus, they have been experimentally and theoretically investigated. ${ }^{6-10}$ Heterointerfaces based on perovskite oxides have heralded the possibility of creating new multifunctional properties in ways that would not have been possible by using single-phase bulk materials. ${ }^{11,12}$ In the $\mathrm{ABO}_{3}$ perovskite oxides with the chemical formula $\mathrm{ABO}_{3}$, the large $\mathrm{A}$ cation is coordinated to twelve anions to form the $\mathrm{AO}_{12}$ cluster, with the $\mathrm{B}$ cation occupying a six-coordinate site of the $\mathrm{BO}_{6}$ cluster which forms a network of corner-sharing $\mathrm{BO}_{6}$ octahedra. Tilting these octahedra leads to deviations from the ideal cubic symmetry. An alternative view consists of $\mathrm{AO}$ and $\mathrm{BO}_{2}$ atomic layers alternatively stacked along the $c$ axis. The novel physical properties that emerge at the heterointerfaces may depend on the atomic layer stacking sequence and the resultant charge redistribution near the heterointerfaces. ${ }^{13-15}$

Among the perovskite based materials, lead zirconate-titanate $\mathrm{PbZr}_{1-x} \mathrm{Ti}_{x} \mathrm{O}_{3}$ solid solutions (often referred to as PZT systems) provide most of the technologically useful ferroelectric and piezoelectric materials which is the dominant electro-active material in applications ${ }^{16}$. Their corresponding properties such as dielectric, piezoelectric, optical and ferroelectric are strongly influenced by the $\mathrm{Zr}: \mathrm{Ti}$ ratio. ${ }^{17-20}$ Their remarkable 
electromechanical and electrical properties are associated with the morphotropic phase boundary (MPB) which is formed by doping antiferroelectric $\mathrm{PbZrO}_{3}$ with ferroelectric $\mathrm{PbTiO}_{3}(\mathrm{PT})$. This MPB occurs with the coexistence of tetragonal (P4mm symmetry FT), monoclinic ( $C m$ symmetry FM) and rhombohedral ( $R 3 c$ symmetry FR) polar distortions of the perovskite structure ${ }^{17}$ which separates two low-temperature ferroelectric phases in the temperature-composition phase diagram. MPB is essential for these properties ${ }^{21}$, and the origin of this extreme response has been under intense debate in recent years. Recently, XRD and neutron diffraction studies used for the average symmetry determination of PZT ceramics and powders were reviewed by Frantti ${ }^{22}$, and particular attention was paid to the structural models proposed for PZT near the MPB and the factors behind the MBP in piezoelectric perovskites. ${ }^{23}$

PZT has a distorted perovskite structure below about $350^{\circ} \mathrm{C}$ with a ferroelectric tetragonal or rhombohedral phase and consequently displays a spontaneous polarization. The polarization direction of the PZT crystal switches between two stable polarization states corresponding to the positive and negative electric bias. This particular feature makes PZT a candidate for nonvolatile ferroelectric random-access memories (NFERAM) ${ }^{24}$ In this respect, Cordero et $a l .{ }^{25}$ reported measurements of the dynamic elastic compliance and dielectric susceptibility of $\mathrm{PbZr}_{1-\mathrm{x}} \mathrm{Ti}_{\mathrm{x}} \mathrm{O}_{3}$ at compositions near the MPB which provides new information on phase transformations between cubic, tetragonal and monoclinic phases. In particular, Rouquette et al. ${ }^{26}$ studied the complex phase transition sequence of $\mathrm{Pb}\left(\mathrm{Zr}_{0.40} \mathrm{Ti}_{0.60}\right) \mathrm{O}_{3}$ under high pressure by neutron diffraction, XRD and resonance Raman spectroscopy. From neutron data and corresponding refined atomic positions, the spontaneous polarization as well as both $(\mathrm{Zr}, \mathrm{Ti}) \mathrm{O}_{6}$ rotations angles and the polarization rotation angle were obtained. Cao et al. ${ }^{27}$ 
studied the piezoelectric response to the (001) electric field in bulk $\mathrm{PbZr}_{1-x} \mathrm{Ti}_{x} \mathrm{O}_{3}$ single crystals $x=0.40-0.50$ near the MPB.

As previously mentioned, the crystal structure of PZT presents ferroelectric properties at room temperature when its phase has a non-centrosymmetric structure; i.e., tetragonal, rhombohedral or orthorhombic. However, the doping effect in the A or B site seems to be an effective way to control ferroelectric behavior of PZT perovskite. Costa et $a l .{ }^{28}$ produced a systematic study of the variation of strontium doping effects on the ferroelectric phase transition temperature in PZT thin films. The results show that the transition temperature decreases with increasing strontium content; no relaxor behavior was observed. Recently, Zhang et $a{ }^{29}$ reported the fabrication and experimental characterization of $\mathrm{PbZr}_{0.40} \mathrm{Ti}_{0.60} \mathrm{O}_{3}$ thin films on glass slices coated with a layer of transparent conductive F-doped tin oxide prepared by chemical solution deposition. Films treated at $650^{\circ} \mathrm{C}$ exhibit a remnant polarization of $29.2 \mu \mathrm{C} / \mathrm{cm}^{2}$. Moret et $a l^{30}$ reported an optical study for epitaxial PZT thin films prepared by metal organic chemical vapor deposition on $\mathrm{SrTiO}_{3}$ substrates with a band gap value of $3.6 \mathrm{eV}$. Experiments conducted by Noheda ${ }^{31}$ revealed the existence of a monoclinic phase between the tetragonal and rhombohedral phase near the MPB region.

Grinberg et al. ${ }^{32,33}$ carried out first principle density-functional-theory (DFT) calculations on a variety of PZT supercells to understand the relationship between properties of constituent atoms, local structure, and compositional phase transitions. They found that the distortions of the structure away from the ideal perovskite structure were governed by an interplay of bonding, electrostatic, and short-range repulsive interactions that depend on the B-cation arrangement. In addition, an accurate description of interatomic interactions can be directly linked to the technologically important macroscopic properties of the material through structure-property correlations 
which provided guidance for the synthesis of next-generation ferroelectric materials. ${ }^{32}$, ${ }^{33}$ Very recently, using inelastic x-ray scattering which revealed soft antiferroelectric fluctuations, Hlinka et al., ${ }^{34}$ investigated the lattice dynamics of a PZT single crystal with a composition close to the MPB .

Experimental and theoretical studies have shown that PZT30/70 doped with W thin films deposited on $\mathrm{LaNiO}_{3}$ bottom electrodes by pulsed laser deposition display strong evidence that the PZTW is less susceptible to fatigue than PZT. ${ }^{35}$ This phenomenon is strongly observed in capacitors formed using platinum electrodes. Furthermore, theoretical investigations have shown that the fatigue phenomenon in the PZT system is associated with the small overlap $\pi$ bonds between $\mathrm{Ti} 3 \mathrm{~d}$ and $\mathrm{O} 2 \mathrm{p}$ states. ${ }^{36}$ In addition, first principle calculations based on density functional theory have been used effectively by many authors to understand the electronic and optical properties of substituted PZT perovskite at both A and B sites. ${ }^{37-40}$ Thus, these studies reveal that modifications in the PZT provoke further unexpected structural properties and qualify it for the development of new functional materials with improved ferroelectric properties. Very recently, two theoretical studies on the $\mathrm{Ba}(\mathrm{Ti}, \mathrm{Zr}) \mathrm{O}_{3}$ system shed light on structural mechanisms that lead to disordered Ti displacements in homovalent-substituted relaxor ferroelectrics as well as its relationship to band-gap behavior. $^{41,42}$ 
The purpose of the present research is to perform a joint experimental analysis and first principle calculations on the ferroelectric and optical properties of PZT thin films prepared by chemical solution deposition. The paper is organized as follows: Sections II and III detail the experimental procedure, the computational method and model systems, respectively. Section IV contains the results and discussion, and finally, our main conclusions are summarized in Section V.

\section{Experimental Procedure}

$\mathrm{PbZr}_{\mathrm{x}} \mathrm{Ti}_{1-\mathrm{x}} \mathrm{O}_{3}$ thin films studied in this work were prepared using a polymeric precursor method $(\mathrm{PPM})$ with $\mathrm{x}=40$ mole\% (referred here as PZT40). Details of the preparation method can be found in the literature. ${ }^{43}$

The viscosity of the deposition solution was adjusted to $15 \mathrm{mPa} / \mathrm{s}$ by controlling the water content. The polymeric precursor solution was spin-coated on substrates by a spinner operating at $7000 \mathrm{rev} . / \mathrm{min}$ for $20 \mathrm{~s}$ using a commercial spinner (spin-coater KW-4B, Chemat Technology). The polymeric precursor solution was deposited onto the substrates via a syringe filter to avoid particular contamination. The substrates were $\mathrm{Pt}$ $(140 \mathrm{~nm}) / \mathrm{Ti}(10 \mathrm{~nm}) / \mathrm{SiO}_{2}(1000 \mathrm{~nm}) / \mathrm{Si}$ and $\mathrm{LaAlO}_{3}(100)$. A two-stage heat treatment was carried out as follows: initial heating at $400^{\circ} \mathrm{C}$ for $4 \mathrm{~h}$ at a heating rate of $5 \mathrm{C}^{\circ} / \mathrm{min}$ in an oxygen atmosphere to pyrolyze the organic materials which was followed by heating at $700^{\circ} \mathrm{C}$ for 2 hours at a heating rate of $5 \mathrm{C}^{\circ} / \mathrm{min}$ for crystallization. The film thickness was controlled by adjusting the number of coatings; each layer was pyrolyzed at $400^{\circ} \mathrm{C}$ and crystallized at $700^{\circ} \mathrm{C}$ before the next layer was coated. These coating/drying operations were repeated until the desired thickness was obtained. The thickness of the thin films were characterized observing the cross section of the films 
using a field-emission scanning electron microscopy (FE-SEM) (FEG-VP Zeiss Supra $35)$.

PZT40 thin films were structurally characterized by XRD in the $2 \theta-\theta$ scan mode which was recorded on a Rigaku D/Max 2400 diffractometer. Typical $2 \theta$ angular scans ranging from $20^{\circ}$ to $60^{\circ}$ in varying steps of $0.02^{\circ}$ were used in these experiments. Raman measurements were taken with a T-64000 Jobin-Yvon triple-monochromator coupled to a charge-coupled device (CCD) detector. An optical microscope with a 100X objective was used to focus the $514.5 \mathrm{~nm}$ line of the Coherent Innova 90 argon laser onto the sample. The power was kept at $15 \mathrm{~mW}$. Infrared analyses were performed by using an Equinox/55 (Bruker) Fourier transform infrared (FT-IR) spectrometer to observe the variations in the chemical bond densities. FT-IR reflectance spectra of the thin films were recorded at room temperature in the frequency range of $350-1200 \mathrm{~cm}^{-1}$ using a $30^{\circ}$ specular reflectance accessory. The optical transmittance of the thin films was measured in the wavelength range of 200 to $800 \mathrm{~nm}$ using a Shimadzu 1240 spectrophotometer.

To measure electrical properties, circular $\mathrm{Au}$ electrodes were prepared by evaporation through a shadow mask with a $4.9 \times 10^{-2} \mathrm{~mm}^{2}$ dot area to obtain an array of capacitors. The deposition was carried out under vacuum down to $10^{-5}$ torr. The polarization hysteresis nature of the film was analyzed using a ferroelectric tester system (Premier Precision from Radiant Technologies, Inc.). The frequency dependence of the dielectric permittivity and the dielectric loss were measured by an Agilent 4294A Precision Impedance Analyzer in the frequency region of $100 \mathrm{~Hz}-10 \mathrm{MHz}$. The capacitance-voltage (C-V) curves were measured using an Agilent 4294A Precision Impedance Analyzer with an AC signal of $50 \mathrm{mV}$ at $100 \mathrm{kHz}$. All measurements were conducted at room temperature. 


\section{Computational Method and Model Systems}

First principle calculations can provide an insight into structural, optical and electronic behavior. Using this method, energies of the different structures can be evaluated, and corresponding optical and electronic properties can be obtained. Calculations were performed with the CRYSTAL06 ${ }^{34}$ program package. The hybrid density-functional method B3LYP involving Becke's three-parameter hybrid non-local exchange functional ${ }^{44}$ combined with the gradient corrected correlation functional by Lee et al. ${ }^{45}$ were selected. Diagonalization of the force matrix was performed at adequate k-points grids (Pack-Monkhorst, 1976) in the reciprocal space. The $k$-points sampling was chosen to be 40 points within the irreducible part of the Brillouin zone. The basis sets were adopted in the following forms: Pb_[DB]-31G, Ti_86-411-d(31), O_6-31G*. Here [DB] denotes the Durand-Barthelat nonrelativistic large effective core potential, and all basis sets can be found at the CRYSTAL home page.

To model both tetragonal symmetric PT and PZT40/60 (100) surfaces, model systems were constructed based on crystals as a set of crystalline planes perpendicular to the given surface; a 2D slab of a finite thickness (periodic in the $\mathrm{x}$-y plane) was cut out. Figure 9 depicts two selected slabs which can be described as follows: i) The PT$\mathrm{TiO}_{2}$ slab consisting of nine alternating $\mathrm{TiO}_{2}$ and $\mathrm{PbO}$ layers (see Figure 9a; and ii) the PT-PbO slab with eleven alternating $\mathrm{PbO}$ and $\mathrm{TiO}_{2}$ layers (see Figure 9b) with a mirror symmetry through the middle of the slab for the tetragonal PT (100) surfaces. To simulate the tetragonal PZT40/60 (100) surface, in the $\mathrm{TiO}_{2}$ terminated slab with nine layers, Ti atoms of the first and the last layers were replaced for the $\mathrm{Zr}$ atoms, see Fig. 10a. In the $\mathrm{PbO}$ terminated slab with eleven layers, $\mathrm{Ti}$ atoms of the fourth and eighth layers were replaced by $\mathrm{Zr}$ atoms (see Figure 10b). In addition, other possibilities were 
explored such as the substitution of $\mathrm{Ti}$ in the second and tenth layers by $\mathrm{Zr}$ (see Figure 10c). Experimental lattice parameters $\mathrm{a}=4.017 \AA$ and $\mathrm{c}=4.14 \AA$ have been selected as the starting point, and geometrric optimization has been carried out until the convergence of calculated slab total energy per cell is smaller than $1 \mathrm{mHa}$.

\section{Results and Discussion}

The crystalline nature of thin films was studied by XRD. Figure 1 shows XRD patterns of PZT40 thin films on a $\mathrm{Pt} / \mathrm{Ti} / \mathrm{SiO}_{2} / \mathrm{Si}$ substrate annealed at different temperatures for 2 hours. With increasing temperature, XRD peaks became sharper and more intense which indicates the enhanced crystallinity of the thin films. Figure 1 illustrates that all diffraction peaks have a perovskite polycrystalline structure with no evidence of preferential orientation or secondary phases except for the strong peak at $2 \theta$ $\sim 39^{\circ}$ which belongs to Pt substrates. Figure 1 also reveals that PZT thin films annealed at $700^{\circ} \mathrm{C}$ exhibit lattice parameters of $0.401 \mathrm{~nm}$ (a-axis) and $0.414 \mathrm{~nm}$ (c-axis). Moreover, the lattice parameter was almost unchanged above $600^{\circ} \mathrm{C}$ which indicates that these PZT40 thin films have good crystallinity within this treatment temperature range. In addition, these values are comparable with reported literature values for the same composition.

Figure 2 shows FT-IR reflectance spectra of PZT40 thin films annealed at different temperatures. For the polymeric precursor of a PZT40 thin film annealed at $150^{\circ} \mathrm{C}$ for 1 hour in air (see Figure 2a), undecomposed organic ligands are still present in the thin film. Vibrations around $1750 \mathrm{~cm}^{-1}$ and at $1400 \mathrm{~cm}^{-1}$ are also observed which can be related to the $\mathrm{C}=\mathrm{O}$ stretching mode for the ester ( $\mathrm{R}-\mathrm{COO}-\mathrm{R})$. Vibrations at $1600 \mathrm{~cm}^{-1}$ and $1390 \mathrm{~cm}^{-1}$ are related to a $\mathrm{COO}^{-}$stretching mode for a bidentate complex. At $400^{\circ} \mathrm{C}$ the spectrum displays a very broad absorption band of the $\mathrm{BO}_{6}$ stretching 
mode, at $900-600 \mathrm{~cm}^{-1}$ which suggests the formation of a solid oxide network disorder. In addition, at $400^{\circ} \mathrm{C}$, the bands associated with undecomposed organic ligands completely disappear. With a temperature increase above $400^{\circ} \mathrm{C}$, the broad absorption band at $900-600 \mathrm{~cm}^{-1}$ becomes sharper and narrower which suggests a structural rearrangement of the $\mathrm{BO}_{6}$ and $\mathrm{AO}_{12}$ units resulting in perovskite phase formation as verified by an increase in absorption band intensities at $690 \mathrm{~cm}^{-1}$ and $428 \mathrm{~cm}^{-1}$, respectively.

The suitability of Raman spectroscopy has been proven for the investigation of very complex systems such as ferroelectric solid solutions. In particular, Deluca et al. ${ }^{46}$ examined several PZT compositions in the proximity of the MPB by Raman spectroscopy. Micro-Raman spectra measured at room temperature after thin films were annealed at different temperatures are depicted in Figure 3. In agreement with XRD and FT-IR analyses, PZT40 thin films show an amorphous structure which maintains the disorder nature of $\mathrm{AO}_{6}$ and $\mathrm{BO}_{12}$ units after drying at $400^{\circ} \mathrm{C}$; a broad shoulder is observed at $773 \mathrm{~nm}$. In addition, with increasing temperature, Raman spectra gradually changed when Raman modes became active and stronger which is an indication of the development of an ordered structure of the $\mathrm{AO}_{6}$ and $\mathrm{BO}_{12}$ units. This result points out that the amorphous phase was gradually transformed to a tetragonal crystalline perovskite phase as corroborated by XRD and FT-IR analysis.

Therefore, as discussed above, $\mathrm{A}_{1}\left({ }^{1} \mathrm{TO}\right), \mathrm{E}\left({ }^{2} \mathrm{TO}\right), \mathrm{B}_{1}+\mathrm{E}, \mathrm{A}_{1}\left({ }^{2} \mathrm{TO}\right), \mathrm{E}\left({ }^{2} \mathrm{LO}\right)+$ $\mathrm{A}\left({ }^{2} \mathrm{LO}\right), \mathrm{E}\left({ }^{3} \mathrm{TO}\right), \mathrm{A}_{1}\left({ }^{3} \mathrm{TO}\right)$ and $\mathrm{E}\left({ }^{3} \mathrm{LO}\right)+\mathrm{A}_{1}\left({ }^{3} \mathrm{LO}\right)$ phonon modes in the Raman spectra provide unambiguous confirmation of the ferroelectric phase of PZT40 thin films obtained by the chemical solution deposition method which corresponds to the tetragonal structure. Figure 4 shows XRD patterns for a $100 \mathrm{~nm}$ thick PZT40 thin film on a (h00) $\mathrm{LaAlO}_{3}$ substrate which used to analyze optical properties. Only reflections 
from the (h00) planes of PZT40 thin films annealed at $700^{\circ} \mathrm{C}$ and $\mathrm{LaAlO}_{3}$ substrates were observed which indicates that thin films were grown epitaxially on the $\mathrm{LaAlO}_{3}$ (100) transparent substrate into the perovskite single phase; no peaks with a pyrochlore phase or a deleterious phase were found. Therefore, thin films are highly (h00) oriented because the matching of lattice parameters between the a-axis of the $\mathrm{LaAlO}_{3}$ substrate and PZT40 thin films is $4.5 \%$. This result verifies that it is possible to obtain epitaxial growth.

Figure 5 shows transmission spectra for $80 \mathrm{~nm}$ thick PZT40 thin films annealed at $700^{\circ} \mathrm{C}$ for 2 hours recorded in the wavelength range of $200-1000 \mathrm{~nm}$ on a (100) $\mathrm{LaAlO}_{3}$ substrate. The PZT40 thin film deposited on a (100) $\mathrm{LaAlO}_{3}$ substrate was highly transparent in the visible region. The optical band gap of the PZT40 thin film was determined in the high absorption region by using the Tauc relation described as

$$
(\alpha h v)^{m}=A\left(h v-E_{g}\right)
$$

where $m$ is a value which characterizes different types of transition $(m=2,1 / 2,2 / 3$ or 1/3 for allowed direct, allowed indirect, forbidden direct and forbidden indirect electronic transitions, respectively), $h v$ is the photon energy, $A$ a constant and $E_{g}$ is the optical band gap value. ${ }^{47-50}$ Thus, the dependence of $(\alpha \mathrm{hv})^{\mathrm{m}}$ versus incident photon energy (hv) yields the Tauc optical band gap $\left(\mathrm{E}_{\mathrm{g}}\right)$ value. As depicted in the inset of Figure 5, the relationship between $(\alpha h v)^{2}$ and $(\alpha h v)^{1 / 2}$ plotted against $h v$ varies linearly in the high energy region of the absorption edge.

Based on the above process, $\mathrm{E}_{\mathrm{g}}$ values were obtained by extrapolating the linear portion of the plot relating $(\alpha h v)^{2}$ and $(\alpha h v)^{1 / 2}$ vs. $h v$ to $(\alpha h v)^{2}=0$ and $(\alpha h v)^{1 / 2}=0$ and considering the direct and indirect nature of the transition process to be $\sim 4.03$ and $\sim 3.10$ $\mathrm{eV}$, respectively. Our calculated band gap value is greater than the band gap value reported by Moret et al. ${ }^{30}$ which was determined by ellipsometry for epitaxial $\mathrm{PbZ}_{\mathrm{x}} \mathrm{Ti}_{1}$ - 
${ }_{x} \mathrm{O}_{3}$ thin films prepared by metal-organic chemical vapor deposition on a $\mathrm{SrTiO}_{3}$ substrate.

Puustinen et al. ${ }^{51}$ showed that as the thickness of PNZT $\left(\mathrm{PbN}_{\mathrm{x}}\left(\mathrm{Z}_{\mathrm{y}} \mathrm{Ti}_{1-\mathrm{y}}\right)_{1-\mathrm{x}} \mathrm{O}_{3}\right)$ thin films deposited on $\mathrm{MgO}$ (100) by pulsed laser deposition decreases from 300 to $150 \mathrm{~nm}$, the band gap values were 4.26 and $4.28 \mathrm{eV}$, respectively, and assumed direct band-toband transition. Pintilie et al. ${ }^{52}$ reported a value of $3.85 \mathrm{eV}$ for a band gap of PZT92/8 thin films deposited by the sol-gel method on single crystal $\operatorname{MgO}(100)$ substrates. Currently, spectroscopy ellipsometry is the optical technique most often utilized to study optical properties of thin films. ${ }^{53-57}$ Recently, Suchaneck et al. ${ }^{55}$ investigated optical properties of PZT thin films prepared by multi-target reactive sputter deposition by ellipsometry spectra. The optical band gap for thin films was calculated using the Tauc relationship by considering direct band gap transition. The results obtained by ellipsometry revealed that, independent of the $\mathrm{Zr} / \mathrm{Ti}$ ratio, band gap energies remain nearly the same for all samples; phonon energy values of , $\mathrm{E}_{\mathrm{g}} 4.04$ and $c a .3 .99 \mathrm{eV}$ were obtained. However, researchers have assumed that the PZT exhibits a direct band gap independent of the $\mathrm{Zr}$ content. $^{20,51,56-59}$ To obtain optical properties, Lee et al. determined band gap values for bulk PZT as a function of a $\mathrm{Zr}$ composition performed within a local density approximation using the VASP package which shows a direct band gap at the $\mathrm{X}$ point. ${ }^{38}$

This result suggests that experimental parameters (i.e, processes, temperature, atmosphere, thickness and substrate) in the preparation of $\mathrm{PbZr}_{\mathrm{x}} \mathrm{Ti}_{1-\mathrm{x}} \mathrm{O}_{3}$ thin films are crucial in determining optical properties of these thin films. Consequently, different band gap results for PZT thin films are expected for the same composition.

Dielectric and ferroelectric properties were determined for PZT thin films with a thickness of $\sim 250 \mathrm{~nm}$ which were annealed at $700^{\circ} \mathrm{C}$ on a $\mathrm{Pt} / \mathrm{Ti} / \mathrm{SiO}_{2} / \mathrm{Si}$ substrate 
measured at room temperature. The room temperature dielectric constant and loss tangent of PZT thin films as a function of measured frequency is recorded in Figure 6. At frequencies range from $10^{2}$ to $10^{6} \mathrm{~Hz}$, both the dielectric constant and the loss tangent do not show noticeable changes with frequencies. These results suggest a good degree of composition homogeneity, thickness uniformity and, more importantly, a small concentration of space charges between electrode/thin film bottom and top PZT/Pt and $\mathrm{Au} / \mathrm{PZT}$ interfaces, respectively. PZT thin films have a dielectric constant and a loss tangent of about 579 and 0.014 , respectively, at $100 \mathrm{KHz}$.

Figure 7 demonstrates the bias dependence of the dielectric constant of the $\mathrm{Au} / \mathrm{PZT} / \mathrm{Pt}$ capacitor at a frequency of $100 \mathrm{KHz}$ at room temperature. The bias voltage was swept quasistatically for each rising and falling bias cycle. The dielectric constant exhibited a large variation with the bias. A hysteresis loop was observed when the applied voltage was swept between positive and negative voltages. Therefore, the butterfly shape indicates that the films reflected ferroelectric behavior at room temperature.

The polarization-bias hysteresis curves of an Au/PZT/Pt capacitor where the PZT layer has an average thickness of $\sim 250 \mathrm{~nm}$ for various applied biases are shown in Figure 8. When the applied bias is increased to higher values, a marked increased in $\mathrm{P}_{\mathrm{r}}$ values occurs, and shaped loops are obtained for PZT thin films which reflects good ferroelectric properties. The measured remanent polarization $\left(\mathrm{P}_{\mathrm{r}}\right)$ value $\sim 23 \mu \mathrm{C} / \mathrm{cm}^{2}$ derived from PZT thin films was obtained by a chemical solution deposition. In addition, this observed value for $\mathrm{P}_{\mathrm{r}}$ is comparable to values reported in the literature for PZT thin films with approximately the same $\mathrm{Zr} / \mathrm{Ti}$ ratio and $\mathrm{Pt} / \mathrm{Ti} / \mathrm{SiO}_{2} / \mathrm{Si}$ substrate. ${ }^{29,}$ 6064 Jegatheesan et al. ${ }^{65}$ reported similar results for PZT thin films with a remanent polarization of $\sim 19 \mu \mathrm{C} / \mathrm{cm}^{2}$ and a dielectric constant of $\sim 450$ at $1000 \mathrm{KHz}$. Zubko et al. 
reported a remanent polarization of $\sim 23 \mu \mathrm{C} / \mathrm{cm}^{2}$ for $\mathrm{PbZr}_{0.40} \mathrm{Ti}_{0.60} \mathrm{O}_{3}$ thin film capacitors using $\mathrm{Pt}$ bottom and $\mathrm{Ir} / \mathrm{IrO}_{2}$ top electrodes. ${ }^{66}$

To further study the optical and electronic properties of PZT, first principle calculations were conducted. Following the definition of Heifets et al., ${ }^{67}$ the cleavage energy $\left(E_{s}^{u}\right)$, the relaxation energy $\left(E_{r e l}\right)$ and the surface energy $\left(E_{s}(i)\right)$ for $\mathrm{PT}-\mathrm{TiO}_{2}$, PT-PbO, PZT-TiO 2 and PZT-PbO have been calculated. This procedure had been used in previous studies. ${ }^{68}$

$E_{s}^{u}$ has been calculated as:

$$
E_{s}^{u}=\frac{1}{4}\left[E_{s l a b}^{u}(P b O)+E_{s l a b}^{u}(X)-E_{b u l k}\right]
$$

where $\boldsymbol{X}$ is $\mathrm{TiO}_{2}$ or $\mathrm{ZrO}_{2}$ and $E_{S}^{u}$ represents unrelaxed $\mathrm{PbO}$ or $\mathrm{TiO}_{2}$ or $\mathrm{ZrO}_{2}$ terminated slab energies. $E_{b u l k}$ is the energy of a supercell constituted by five $\mathrm{PbTiO}_{3}$ units where two Ti atoms are replaced by $\mathrm{Zr}$ atoms, $n$ is the number of atomic layers, and a factor $1 / 4$ comes from the fact that we create four surfaces upon cleavage procedure. $E_{r e l}$ for each $\mathrm{PbO}, \mathrm{TiO}_{2}$ and $\mathrm{ZrO}_{2}$, have been calculated as:

$$
E_{\text {rel }}(i)=\frac{1}{2}\left[E_{\text {slab }}(i)-E_{\text {slab }}^{u}(i)\right]
$$

where $E_{\text {slab }}(i)$ is the slab energy after relaxation, and $i$ is $\mathrm{PbO}$ or $\mathrm{TiO}_{2}$ or $\mathrm{ZrO}_{2}$ termination. The last one, $E_{S}(i)$, is the sum of the cleavage and relaxation energies:

$$
E_{s}(i)=E_{s}^{u}(i)+E_{r e l}(i)
$$

Table 1 shows these energies as a function of surface termination. A comparison of the PT and PZT system shows a compensation of $E_{s}^{u}$ values (higher in PZT than PT) with $E_{r e l}$ values (lower in PZT than PT) and similar surface energy 
values. Table 1 also shows collected values for two more stable PZT system models. The possibility of replacing $\mathrm{Zr}$ atoms by $\mathrm{Ti}$ atoms in the third and seventh layers of the nine-layer $\mathrm{TiO}_{2}$ terminated slab was studied which resulted in small favored combinations for PZT- PbO slabs.

The calculated direct and indirect optical gap values for PT and PZT systems are summarized in Table 2. From an analysis of the band structure of $\mathrm{TiO}_{2}$ and $\mathrm{PbO}$ terminated surfaces to the PT, there is a direct band gap energy of $3.84 \mathrm{eV}$ for the PT$\mathrm{TiO}_{2}$ slab with the maximum energy for $\mathrm{VB}$ and the minimum energy for $\mathrm{CB}$ located at the $\Gamma$ point. However, the $\mathrm{PT}-\mathrm{PbO}$ slab has an indirect band gap energy of $3.98 \mathrm{eV}$ between the points $\mathrm{X}-\mathrm{M}$. The top of the upper VB for the two possibilities of PZT $40 / 60, \mathrm{PbO}\left(4^{\text {th }} / 8^{\text {th }}\right)$ and $\mathrm{PbO}\left(2^{\text {nd }} / 10^{\text {th }}\right)$ is located at the $\mathrm{X}$ point, and the bottom of the lowest $\mathrm{CB}$ is located at the $\mathrm{M}$ point with indirect gaps of $3.67 \mathrm{eV}$ and $3.45 \mathrm{eV}$, respectively. The top of the upper VB for the PZT40/60 in the $\mathrm{ZrO}_{2}$ terminated surface is located at the $\mathrm{X}$ point, and the bottom of the $\mathrm{CB}$ is located at the $\Gamma$ point which yields an indirect gap value of $3.63 \mathrm{eV}$.

An analysis of the results shows that in the PZT40/60 system, gap values are smaller than gap values in the pure system (PT) for both terminations which can be associated with the substitution Ti by $\mathrm{Zr}$ (see Figure 10). This change increases the $\mathrm{Zr}-$ $\mathrm{O}$ bond distance and decreases the $\mathrm{Ti}-\mathrm{O}$ bond distance with respect to previous and subsequent layers (see Table 3). Therefore, this behavior can be assigned to a symmetry breaking process of $\mathrm{TiO}_{6} / \mathrm{ZrO}_{6}$ octahedron clusters for both terminations.

Figures $11 \mathrm{a}$ and $11 \mathrm{~b}$ depict the calculated total and projected densities of state on atoms and orbitals of $\mathrm{PT}$ for $\mathrm{PbO}$ and $\mathrm{TiO}_{2}$ terminations. For both surfaces, the valence bands are composed of $2 p$ orbitals of $\mathrm{O}$ atoms but with a minor $2 p_{x}$ contribution in $\mathrm{TiO}_{2}$ terminations. The first conduction band for both terminations shows many differences. 
The PbO-terminated slab is derived mostly from $3 d_{x z}$ of the Ti atom. On the other hand, in a $\mathrm{TiO}_{2}$ terminated slab, the conduction band with a broadened aspect has a mainly $\mathrm{Ti}$ $3 d_{x z}$ and $3 d_{y z}$ character with a minor contribution from $3 d_{z^{2}}$ orbitals.

Electronic properties of perfect cubic and defective (oxygen vacancy) PT and PZ perovskites have been especially revised by Piskunov et al ${ }^{69-72}$ at hybrid B3PW DFT level. New energy levels located in the band gap due to $F$ centers are compared in both bulk and surface PT and PZ systems. In our case the exploration of the total and projected DOS for the PZT40/60 system generates important differences with regard to the PT system which is more relevant in the two types of $\mathrm{PbO}$ terminations $\mathrm{PbO}\left(4^{\text {th }} / 8^{\text {th }}\right)$ and $\mathrm{PbO}\left(2^{\text {nd }} / 10^{\text {th }}\right)$ surfaces studied. In the $\mathrm{PbO}\left(4^{\text {th }} / 8^{\text {th }}\right)$ slab, the principal component of the top of the VB consists mainly of the $\mathrm{O} 2 p_{x}$ orbital. The $\mathrm{CB}$ is mainly composed of $3 d_{x z}$ and $3 d_{x y} \mathrm{AO}$ of $\mathrm{Ti}$ atoms and $6 p \mathrm{AO}$ of $\mathrm{Pb}$ atoms (see Figure 12a). Figure 12b shows the projected DOS for PZT- $\mathrm{ZrO}_{2}$. An analysis of the principal AO component of the top of the $\mathrm{VB}$ consists mainly of $\mathrm{O} 2 p_{x}$ states as in $\mathrm{PbO}\left(4^{\text {th }} / 8^{\text {th }}\right)$ termination. The $\mathrm{CB}$ is composed mainly of $\mathrm{Ti} 3 d_{x z}$ orbitals which dominate the Ti $3 d_{y z}$ and $6 p$ of $\mathrm{Pb}$ atoms. However, in the $\mathrm{PbO}\left(2^{\text {nd }} / 10^{\text {th }}\right)$ termination, the $\mathrm{VB}$ is composed of $2 p$ orbitals of $\mathrm{O}$ atoms, and the $\mathrm{CB}$ consists mainly $\mathrm{Ti} 3 d_{x z}$ and $6 p_{x}$ and $6 p_{z}$ contributions of $\mathrm{Pb}$ atoms (see Figure 13).

Thus, although the $\mathrm{Zr}$ AOs do not contribute directly to the gap energy range, $\mathrm{O}$, $\mathrm{Ti}$, and $\mathrm{Pb} \mathrm{AOs}$ are influenced by the $\mathrm{Zr}$ substitution. This result shows that adding $\mathrm{Zr}$ atoms to the PT system decreases the overlapping between $\mathrm{O} 2 p$ and Ti $3 d$ orbitals. It is apparent that contributions of the $\mathrm{O} 2 p$ and Ti $3 d$ states into the valence band (and the conduction band) of PZT40/60 facets depend on the position of these atoms in the corresponding surfaces. 


\section{Conclusions}

A joint experimental and theoretical study has been devoted to understanding the structural, optical and electronic properties of PZT thin films. PZT40/60 thin films have been successfully grown on $\mathrm{Pt} / \mathrm{Ti} / \mathrm{SiO}{ }_{2} / \mathrm{Si}$ and $\mathrm{LaAlO}_{3}$ (100) substrates using the chemical solution deposition method. To better understand the optical experimental results, the electronic band structure of the $\mathrm{PbTiO}_{3}$ (PT) system and tetragonal $\mathrm{PbZr}_{0.40} \mathrm{Ti}_{0.60} \mathrm{O}_{3}(\mathrm{PZT} 40 / 60)$ was calculated by first principle calculations. In addition, structural and electronic properties of the $\mathrm{PbO}$ and $\mathrm{ZrO}_{2}$ terminated (100) surface of tetragonal PZT40/60 were calculated. The main conclusions can be summarized as follows: i) XRD analysis reveals that thin films grew with high (100) orientations on $\mathrm{LaAlO}_{3}$ (100) substrates while on $\mathrm{Pt} / \mathrm{Ti} / \mathrm{SiO}_{2} / \mathrm{Si}$ substrates the thin films had a polycrystalline growth; ii) the tetragonal phase was confirmed by Raman analysis; iii) thin films exhibit ferroelectric and dielectric properties with a remanent polarization of $23 \mu \mathrm{C} / \mathrm{cm}^{2}$, while the dielectric constant values and loss tangent values are 579 and 0.014 at $100 \mathrm{KHz}$, respectively; iv) the transmittance curve of PZT40/60 thin films on $\mathrm{LaAlO}_{3}(100)$ substrates had an optical band gap of 4.03 and $3.10 \mathrm{eV}$ for the direct and indirect transition process, respectively; v) the PT system shows indirect and direct optical band gaps of 3.84 and $3.98 \mathrm{eV}$ for $\mathrm{PT}-\mathrm{PbO}$ and $\mathrm{PT}_{-} \mathrm{TiO}_{2}$ terminations, respectively; vi) the PZT40/60 system shows indirect optical band gaps of 3.63/3.45 and $3.67 \mathrm{eV}$ for the $\mathrm{PbO}\left(4^{\text {th }} / 8^{\text {th }}\right) / \mathrm{PbO}\left(2^{\text {nd }} / 10^{\text {th }}\right)$ and $\mathrm{ZrO}_{2}$ terminations, respectively (these theoretical values are in agreement with the trends of experimental data); vii) our theoretical results indicate that the introduction of $\mathrm{Zr}$ in the $\mathrm{Ti}$ site causes a distortion in the crystal lattice which changes $\mathrm{Ti}-\mathrm{O}$ and $\mathrm{Zr}-\mathrm{O}$ bond distances which can be associated with a breaking symmetry process of the octahedral clusters, $\mathrm{TiO}_{6} / \mathrm{ZrO}_{6}$, as polyhedra constituents of this material for both terminations and viii) an analysis of density of 
states reveals that atomic orbitals of $\mathrm{Zr}$ atom do not contribute directly to the band gap energy range. However, adding $\mathrm{Zr}$ atoms to the PT system decreases the overlapping between $\mathrm{O} 2 p$ and $\mathrm{Ti} 3 d$ orbitals.

\section{Acknowledgments}

This work is supported by the Spanish MALTA-Consolider Ingenio 2010 Program (Project CSD2007-00045), Bancaixa Foundation (P11B2009-08), Spanish-Brazilian Program (PHB2009-0065-PC), Ciencia e Innovación for project CTQ2009-14541-C02, Generalitat Valenciana for Prometeo/2009/053 project, and by the financial support of the Brazilian research financing institutions: CAPES, CNPq and FAPESP. The authors also acknowledge the Servei Informatica, Universitat Jaume I for generous allotment of computer time.

\section{References}

1. M. Dawber, K. M. Rabe and J. F. Scott, Reviews of Modern Physics, 2005, 77, 1083-1130.

2. N. Setter, D. Damjanovic, L. Eng, G. Fox, S. Gevorgian, S. Hong, A. Kingon, H. Kohlstedt, N. Y. Park, G. B. Stephenson, I. Stolitchnov, A. K. Taganstev, D. V. Taylor, T. Yamada and S. Streiffer, Journal of Applied Physics, 2006, 100, 051606.

3. A. Brinkman, M. Huijben, M. Van Zalk, J. Huijben, U. Zeitler, J. C. Maan, W. G. Van der Wiel, G. Rijnders, D. H. A. Blank and H. Hilgenkamp, Nature Materials, 2007, 6, 493-496. 
4. J. L. Maurice, C. Carretero, M. J. Casanove, K. Bouzehouane, S. Guyard, E. Larquet and J. P. Contour, Physica Status Solidi a-Applications and Materials Science, 2006, 203, 2209-2214.

5. J. B. Neaton and K. M. Rabe, Applied Physics Letters, 2003, 82, 1586-1588.

6. N. Izyumskaya, Y. Alivov, S. J. Cho, H. Morkoc, H. Lee and Y. S. Kang, Critical Reviews in Solid State and Materials Sciences, 2007, 32, 111-202.

7. R. Kagimura and D. J. Singh, Physical Review B, 2008, 78, 174105.

8. B. Xu, X. Li, J. Sun and L. Yi, European Physical Journal B, 2008, 66, 483487.

9. F. C. Zhang, Z. Y. Zhang, W. H. Zhang, J. F. Yan and J. N. Yun, Acta PhysicoChimica Sinica, 2009, 25, 61-66.

10. T. Shimada, S. Tomoda and T. Kitamura, Journal of Physics-Condensed Matter, 2010, 22, 355901.

11. C. H. Ahn, J. M. Triscone and J. Mannhart, Nature, 2003, 424, 1015-1018.

12. D. D. Fong, G. B. Stephenson, S. K. Streiffer, J. A. Eastman, O. Auciello, P. H. Fuoss and C. Thompson, Science, 2004, 304, 1650-1653.

13. H. Kumigashira, D. Kobayashi, R. Hashimoto, A. Chikamatsu, M. Oshima, N. Nakagawa, T. Ohnishi, M. Lippmaa, H. Wadati, A. Fujimori, K. Ono, M. Kawasaki and H. Koinuma, Applied Physics Letters, 2004, 84, 5353-5355.

14. A. Ohtomo, D. A. Muller, J. L. Grazul and H. Y. Hwang, Nature, 2002, 419, 378-380.

15. S. Okamoto and A. J. Millis, Nature, 2004, 428, 630-633.

16. E. Cross, Nature, 2004, 432, 24-25.

17. B. Noheda and D. E. Cox, Phase Transitions, 2006, 79, 5-20. 
18. F. Chen, J. R. Cheng, S. W. Yu and Z. Y. Meng, Journal of Materials ScienceMaterials in Electronics, 2010, 21, 514-518.

19. J. S. Cross, S. H. Kim, S. Wada and A. Chatterjee, Science and Technology of Advanced Materials, 2010, 11, 044402.

20. E. Defay, T. Lacrevaz, T. T. Vo, V. Sbrugnera, C. Bermond, M. Aid and B. Flechet, Applied Physics Letters, 2009, 94, 052901.

21. W. H. Duan and Z. R. Liu, Current Opinion in Solid State \& Materials Science, 2006, 10, 40-51.

22. J. Frantti, Journal of Physical Chemistry B, 2008, 112, 6521-6535.

23. J. Frantti, Fujioka, Y., Zhang, J., Vogel, S. C., Wang, Y., Zhao, Y., Nieminen, R. M., Journal of Physical Chemistry B, 2009, 113, 7967-7972.

24. J. F. Scott and C. A. Paz de Araujo, Science, 1989, 246, 1400-1405.

25. F. Cordero, F. Craciun and C. Galassi, Journal of Physics and Chemistry of Solids, 2008, 69, 2172-2176.

26. J. Rouquette, J. Haines, G. Fraysse, A. Al-Zein, V. Bornand, M. Pintard, P. Papet, S. Hull and F. A. Gorelli, Inorganic Chemistry, 2008, 47, 9898-9904.

27. Y. Cao, G. Sheng, J. X. Zhang, S. Choudhury, Y. L. Li, C. A. Randall and L. Q. Chen, Applied Physics Letters, 2010, 97, 252904.

28. F. M. Pontes, M. S. Galhiane, L. S. Santos, A. Gavino, L. A. Petit, D. S. L. Pontes, E. Longo, A. J. Chiquito and C. E. F. Costa, Applied Physics aMaterials Science \& Processing, 2009, 95, 693-698.

29. T. Zhang, G. J. Hu, H. J. Bu, J. Wu, J. H. Chu and N. Dai, Journal of Applied Physics, 2010, 107, 084103.

30. M. P. Moret, M. A. C. Devillers, K. Worhoff and P. K. Larsen, Journal of Applied Physics, 2002, 92, 468-474. 
31. B. Noheda, J. A. Gonzalo, L. E. Cross, R. Guo, S. E. Park, D. E. Cox and G. Shirane, Physical Review B, 2000, 61, 8687-8695.

32. I. Grinberg, V. R. Cooper and A. M. Rappe, Physical Review B, 2004, 69, 144118.

33. I. Grinberg and A. M. Rappe, Phase Transitions, 2007, 80, 351-368.

34. J. Hlinka, Ondrejkovic, P., Kempa, M., Borissenko, E., Krisch, M., Long, X., Ye, Z. -G., Physical Review B, 2011, 83, 140101.

35. Z. Zhang, L. Lu, C. Shu, P. Wu and W. Song, Journal of Applied Physics, 2007, 102, 074119.

36. K. Miura and M. Tanaka, Japanese Journal of Applied Physics Part 1-Regular Papers Short Notes \& Review Papers, 1996, 35, 2719-2725.

37. I. Grinberg, V. R. Cooper and A. M. Rappe, Nature, 2002, 419, 909-911.

38. H. Lee, Y. S. Kang, S. J. Cho, B. Xiao, H. Morkoc, T. D. Kang, G. S. Lee, J. Li, S. H. Wei, P. G. Snyder and J. T. Evans, Journal of Applied Physics, 2005, 98, 094108

39. J. A. Rodriguez, A. Etxeberria, L. Gonzalez and A. Maiti, Journal of Chemical Physics, 2002, 117, 2699-2709.

40. Z. Zhang, P. Wu, K. P. Ong, L. Lu and C. Shu, Physical Review B, 2007, 76, 125102.

41. C. Laulhe, A. Pasturel, F. Hippert and J. Kreisel, Physical Review B, 2010, 82, 132102.

42. I. Levin, E. Cockayne, V. Krayzman, J. C. Woicik, S. Lee and C. A. Randall, Physical Review B, 2011, 83, 094122. 
43. F. M. Pontes, E. R. Leite, M. S. J. Nunes, D. S. L. Pontes, E. Longo, R. Magnani, P. S. Pizani and J. A. Varela, Journal of the European Ceramic Society, 2004, 24, 2969-2976.

44. A. D. Becke, Journal of Chemical Physics, 1993, 98, 5648-5652.

45. C. T. Lee, W. T. Yang and R. G. Parr, Physical Review B, 1988, 37, 785-789.

46. H. F. M. Deluca, N. Tonari, C. Capiani, N. Hasuike, K. Kisoda, C. Galassid and H. Harima, J. Raman Spectrsocopy, 2011, 42, 488.

47. M. Bousquet, J. R. Duclere, E. Orhan, A. Boulle, C. Bachelet and C. Champeaux, Journal of Applied Physics, 2010, 107, 104107.

48. Q. Z. Liu, J. M. Dai, Z. L. Liu, X. B. Zhang, G. P. Zhu and G. H. Ding, Journal of Physics D-Applied Physics, 2010, 43, 455401.

49. F. M. Pontes, E. R. Leite, D. S. L. Pontes, E. Longo, E. M. S. Santos, S. Mergulhao, P. S. Pizani, F. Lanciotti, T. M. Boschi and J. A. Varela, Journal of Applied Physics, 2002, 91, 5972-5978.

50. F. M. Pontes, D. S. L. Pontes, E. R. Leite, E. Longo, E. M. S. Santos, S. Mergulhao and J. A. Varela, Journal of Sol-Gel Science and Technology, 2003, 27, 137-147.

51. J. Puustinen, J. Lappalainen and V. Lantto, Thin Solid Films, 2008, 516, 64586463.

52. L. Pintilie, I. Boerasu, M. Gomes and M. Pereira, Thin Solid Films, 2004, 458, 114-120.

53. I. Aulika, V. Zauls, K. Kundzins, M. Kundzins and S. Katholy, Journal of Optoelectronics and Advanced Materials, 2003, 5, 755-761. 
54. D. Chvostova, L. Pajasova and V. Zelezny, in Physica Status Solidi C - Current Topics in Solid State Physics, Vol 5, No 5, edited by H. Arwin, U. Beck and M. Schubert (2008), Vol. 5, pp. 1362-1365.

55. G. Suchaneck, D. Chvostova, J. Kousal, V. Zelezny, A. Lynnyk, L. Jastrabik, G. Gerlach and A. Dejneka, Thin Solid Films, 2011, 519, 2885-2888.

56. X. G. Tang, Q. X. Liu, L. L. Jiang and A. L. Ding, Materials Chemistry and Physics, 2007, 103, 329-333.

57. S. H. Yang, Y. L. Zhang and D. Mo, Materials Science and Engineering B-Solid State Materials for Advanced Technology, 2006, 127, 117-122.

58. S. K. Pandey, A. R. James, R. Raman, S. N. Chatterjee, A. Goyal, C. Prakash and T. C. Goel, Physica B-Condensed Matter, 2005, 369, 135-142.

59. M. M. Zhu, Z. H. Du and J. Ma, Journal of Applied Physics, 2010, 108, 113119.

60. R. Bouregba, N. Sama, C. Soyer, G. Poullain and D. Remiens, Journal of Applied Physics, 2010, 107, 104102.

61. J. W. Li, H. Kameda, B. N. Q. Trinh, T. Miyasako, P. T. Tue, E. Tokumitsu, T. Mitani and T. Shimoda, Applied Physics Letters, 2010, 97, 102905.

62. B. T. Liu, J. W. Zhao, X. H. Li, Y. Zhou, F. Bian, X. Y. Wang, Q. X. Zhao, Y. L. Wang, Q. L. Guo, L. X. Wang and X. Y. Zhang, Applied Physics Letters, 2010, 96, 252904.

63. N. Sama, R. Herdier, D. Jenkins, C. Soyer, D. Remiens, M. Detalle and R. Bouregba, Journal of Crystal Growth, 2008, 310, 3299-3302.

64. X. Zhao, J. Y. Dai, X. G. Tang, J. Wang, H. L. W. Chan and C. L. Choy, Applied Physics a-Materials Science \& Processing, 2005, 81, 997-1000.

65. P. Jegatheesan, H. K. Yadav, V. Gupta and N. V. Giridharan, Materials Letters, 2011, 65, 901-904. 
66. P. Zubko, D. J. Jung and J. F. Scott, Journal of Applied Physics, 2006, 100, 114113.

67. E. Heifets, R. I. Eglitis, E. A. Kotomin, J. Maier and G. Borstel, Physical Review B, 2001, 64, 235417.

68. S. de Lazaro, E. Longo, J. R. Sambrano and A. Beltran, Surface Science, 2004, 552, 149-159.

69. S. Piskunov, E. Heifets, R. I. Eglitis and G. Borstel, Computational Materials Science, 2004, 29, 165-178.

70. S. Piskunov, A. Gopeyenko, E. A. Kotomin, Y. F. Zhukovskii and D. E. Ellis, Computational Materials Science, 2007, 41, 195-201.

71. E. A. Kotomin, S. Piskunov, Y. F. Zhukovskii, R. I. Eglitis, A. Gopejenko and D. E. Ellis, Physical Chemistry Chemical Physics, 2008, 10, 4258-4263.

72. Y. F. Zhukovskii, E. A. Kotomin, S. Piskunov and D. E. Ellis, Solid State Communications, 2009, 149, 1359-1362. 
Table 1. $E_{s}^{u}, E_{r e l}$ and $E_{s}(i)$ for PT and PZT40/60 as a function of termination. In parenthesis is located the layer in which Ti atom is substituted by $\mathrm{Zr}$.

\begin{tabular}{llccc}
\hline Systems & Termination & $E_{s}^{u}$ & $E_{\text {rel }}$ & $E_{S}(i)(\mathbf{e V} /$ cell $)$ \\
\hline $\mathrm{PbTiO}_{3}$ & $\mathrm{PbO}$ & 0.153 & -0.036 & 3.184 \\
& $\mathrm{TiO} 2$ & & -0.036 & 3.184 \\
\hline $\mathrm{PZT} 40 / 60$ & $\mathrm{PbO}\left(4^{\mathrm{th}} / 8^{\mathrm{th}}\right)$ & \multirow{2}{*}{0.200} & -0.092 & 2.936 \\
& $\mathrm{ZrO} 2\left(1^{\mathrm{st}} / 9^{\mathrm{th}}\right)$ & & -0.075 & 3.410 \\
\cline { 2 - 5 } & $\mathrm{PbO}\left(2^{\mathrm{nd}} / 10^{\mathrm{th}}\right)$ & & -0.087 & 3.136 \\
& $\mathrm{ZrO} 2\left(1^{\mathrm{st}} / 9^{\mathrm{th}}\right)$ & 0.202 & -0.075 & 3.473 \\
\hline
\end{tabular}


Table 2. Calculated optical gap (eV) for the PT-TiO $, \mathrm{PT}-\mathrm{PbO}, \mathrm{PZT} 40 / 60-\mathrm{ZrO}_{2}$ and PZT40/60-PbO terminations.

\begin{tabular}{llccccc}
\hline & & PT-TiO & PT-PbO & PZT-ZrO & $\begin{array}{c}\text { PZT-PbO } \\
\left(4^{\text {th }} / 8^{\text {th }}\right)\end{array}$ & $\begin{array}{c}\text { PZT-PbO } \\
\left(2^{\text {nd }} / 10^{\text {th }}\right)\end{array}$ \\
\hline Direct & $\Gamma$ & $\mathbf{3 . 8 4}$ & 4.04 & 4.03 & 4.32 & \\
Indirect & $\mathrm{X}-\Gamma$ & - & $\mathbf{3 . 9 8}$ & - & - & - \\
& $\mathrm{X}-\mathrm{M}$ & - & - & - & $\mathbf{3 . 6 3}$ & $\mathbf{3 . 4 5}$ \\
& $\mathrm{X}^{\prime}-\Gamma$ & - & - & $\mathbf{3 . 6 7}$ & - & - \\
\hline
\end{tabular}


Table 3. Displacements of the atoms $\Delta \mathrm{Z}(\AA)$, of uppermost two layers from their perfect lattice positions in PZT 40/60 surface. c refers to the central layer.

\begin{tabular}{|c|c|c|c|c|c|}
\hline \multicolumn{2}{|c|}{$\mathrm{PZT}-\mathrm{ZrO}_{2}$} & \multicolumn{2}{|c|}{$\mathrm{PZT}-\mathrm{PbO}\left(4^{\mathrm{th}} / 8^{\mathrm{th}}\right)$} & \multicolumn{2}{|c|}{$\mathrm{PZT}-\mathrm{PbO}\left(2^{\text {nd }} / 10^{\text {th }}\right)$} \\
\hline$\Delta \mathrm{Z}(\AA)$ & layer & $\Delta \mathrm{Z}(\AA)$ & layer & $\Delta \mathrm{Z}(\AA)$ & layer \\
\hline 0.2528 & $1-2$ & 0.0121 & $1-2$ & 0.2306 & $1-2$ \\
\hline-0.0489 & $2-3$ & -0.0288 & $2-3$ & 0.1377 & $2-3$ \\
\hline 0.0326 & $3-4$ & 0.2112 & $3-4$ & -0.0156 & $3-4$ \\
\hline \multirow[t]{2}{*}{-0.0010} & 4-c & 0.1585 & $4-5$ & 0.0031 & $4-5$ \\
\hline & & -0.0168 & $5-c$ & -0.0011 & $5-c$ \\
\hline
\end{tabular}


Figure 1. XRD patterns of PZT40/60 thin films annealed at various temperatures. (a) $400^{\circ} \mathrm{C}$; (b) $500^{\circ} \mathrm{C}$; (c) $600^{\circ} \mathrm{C}$ and (d) $700^{\circ} \mathrm{C}$.

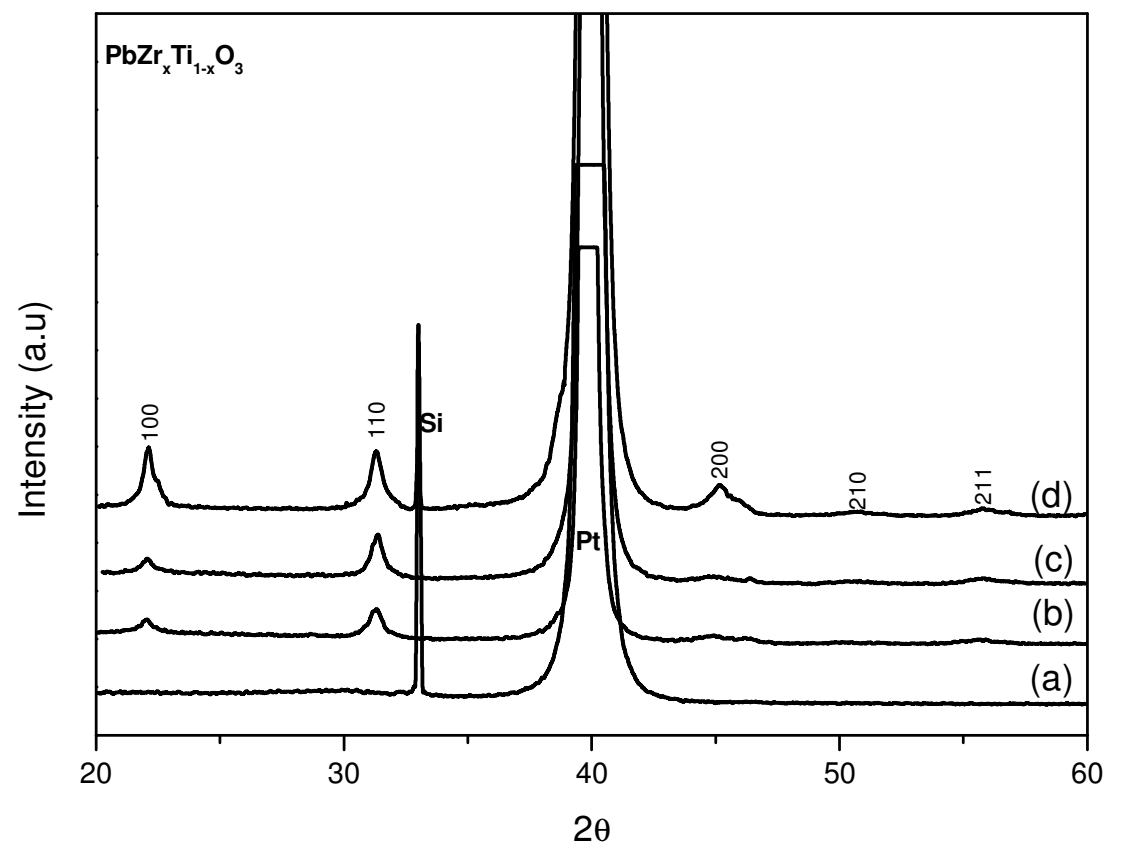


Figure 2. FT-IR spectra of PZT40/60 thin films on $\mathrm{Pt} / \mathrm{Ti} / \mathrm{SiO}_{2} / \mathrm{Si}$ substrate annealed at various temperatures. (a) as-prepared thin films; (b) $400^{\circ} \mathrm{C}$; (c) $500^{\circ} \mathrm{C}$; (d) $600^{\circ} \mathrm{C}$, and (d) $700^{\circ} \mathrm{C}$.

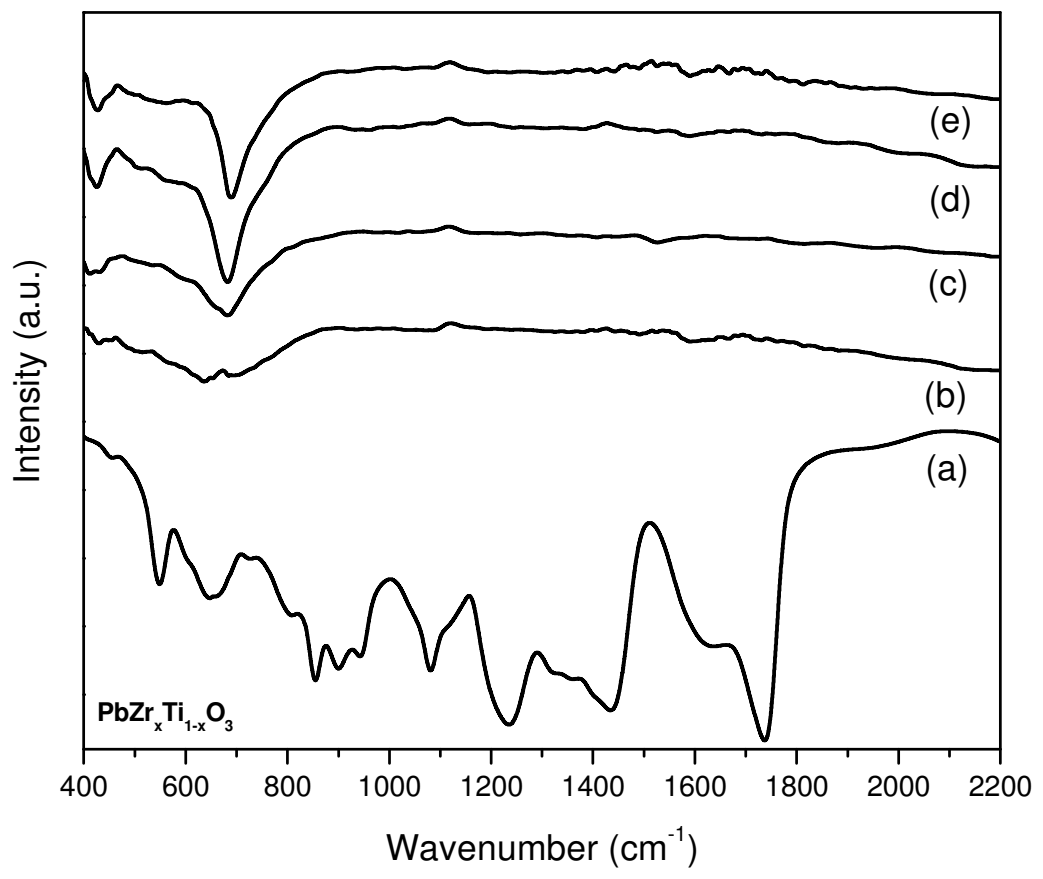


Figure 3. Raman spectra at room temperature for PZT40/60 thin films annealed at varius temperatures. (a) $400^{\circ} \mathrm{C}$; (b) $500^{\circ} \mathrm{C}$; (c) $600^{\circ} \mathrm{C}$ and (d) $700^{\circ} \mathrm{C}$.

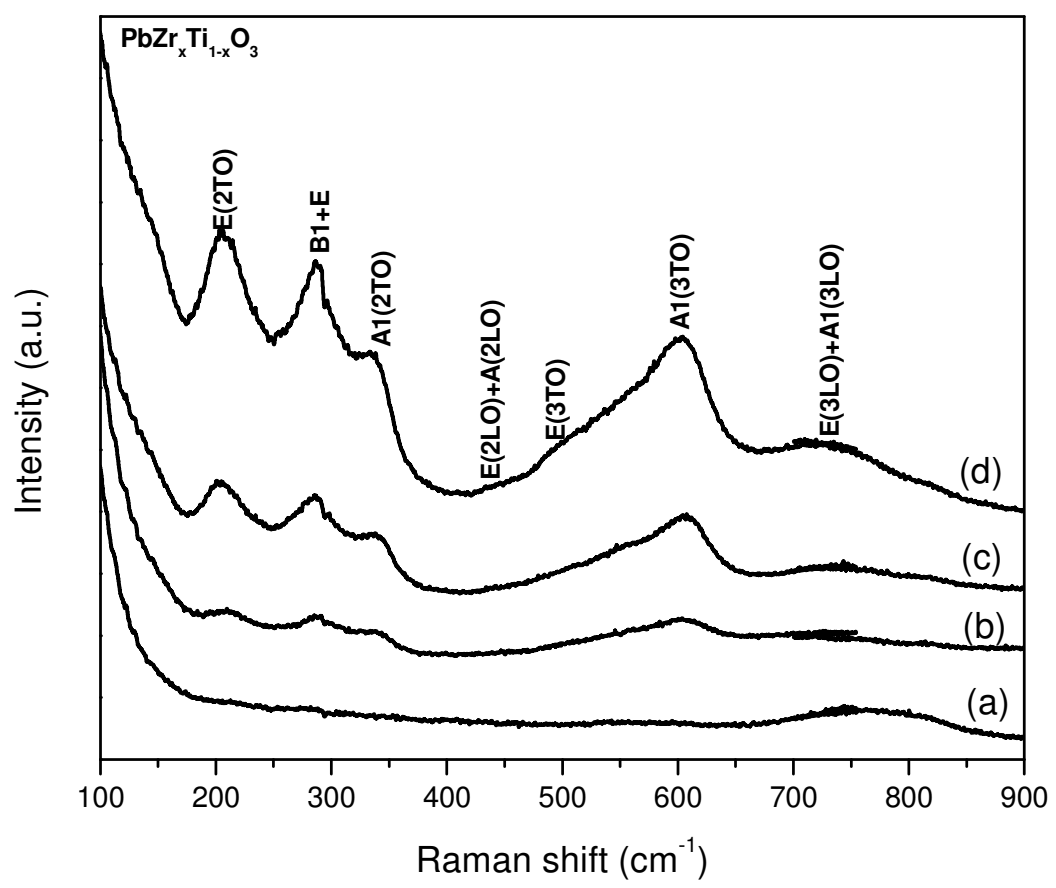


Figure 4. X-ray diffraction patterns for the PZT40/60 thin films deposited on $\mathrm{LaAlO}_{3}$ (100) substrate.

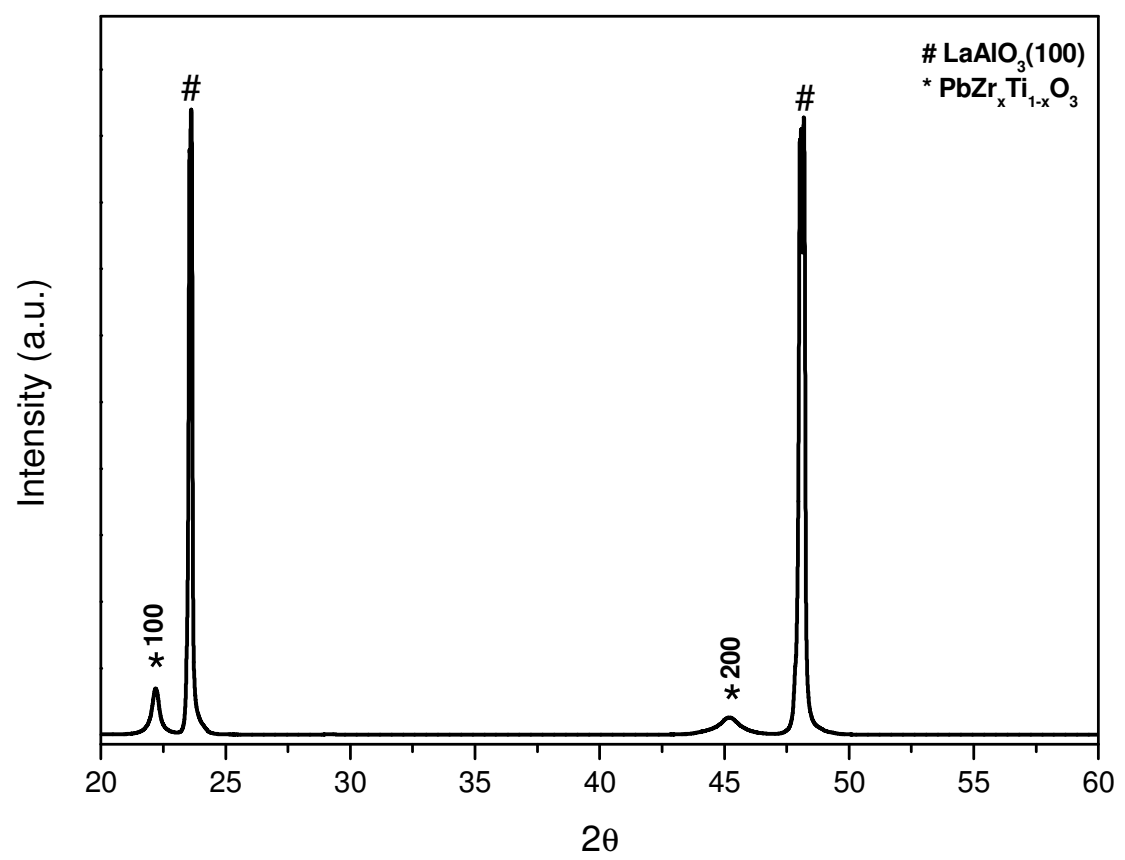


Figure 5. Optical transmission spectra measured of PZT40/60 thin films on $\mathrm{LaAlO}_{3}(100)$ substrate. The inset shows the plots of $(h v \alpha)^{2}$ versus $h v$ and $(h v \alpha)^{1 / 2}$ versus $h v$.

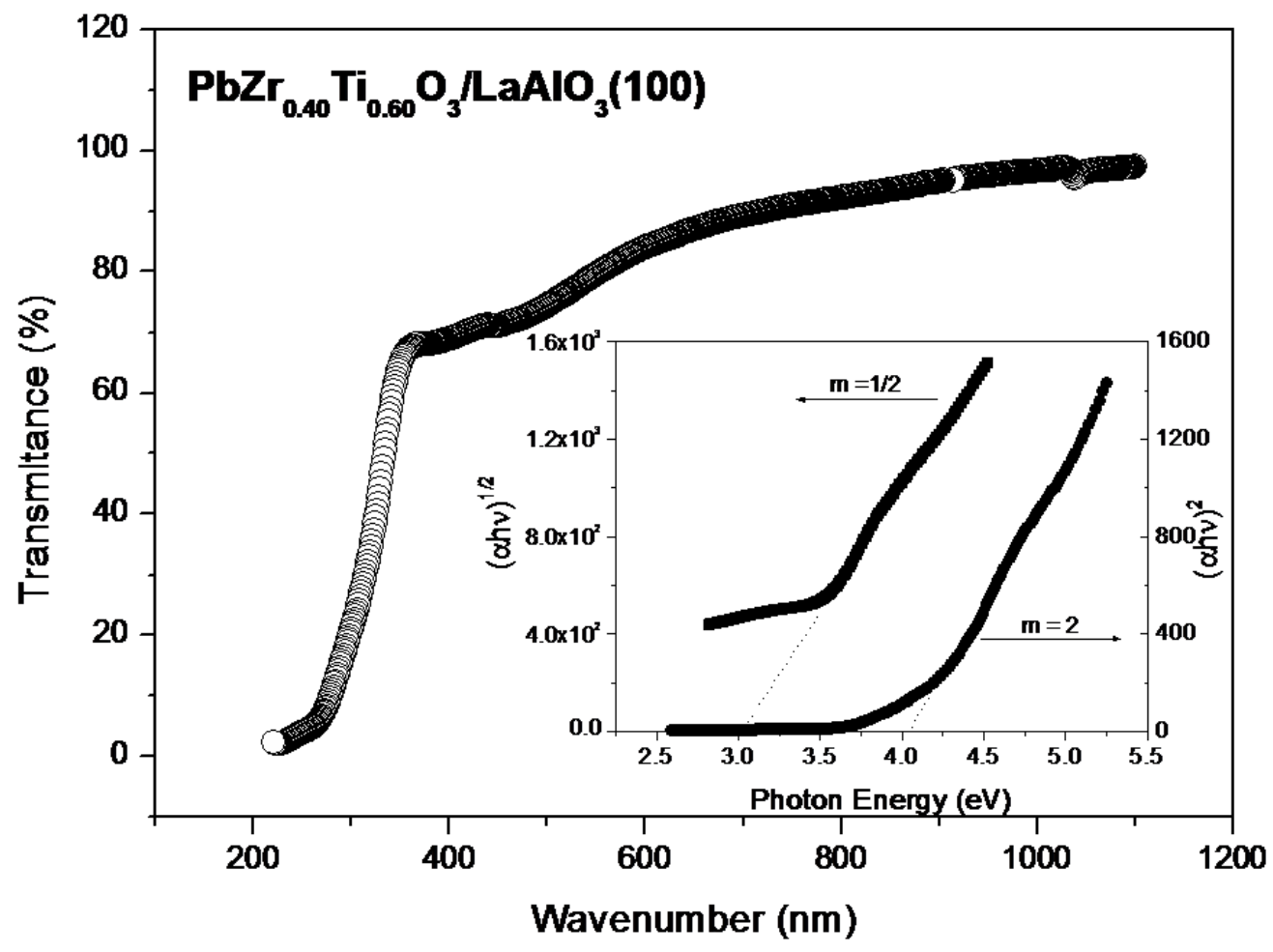


Figure 6. The variation of dielectric constant and loss tangent for PZT40/60 thin films deposited on $\mathrm{Pt} / \mathrm{Ti} / \mathrm{SiO}_{2} / \mathrm{Si}$ substrates and annealed at $700^{\circ} \mathrm{C}$.

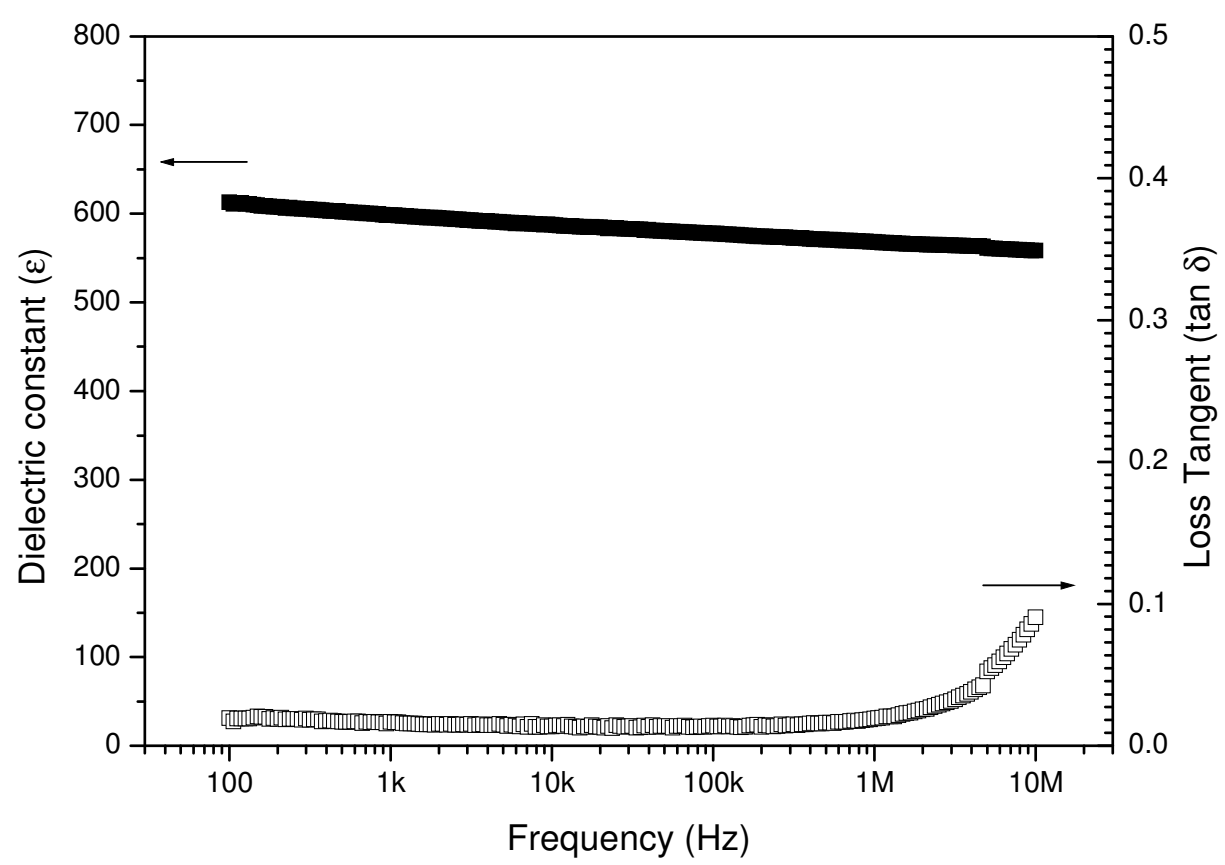


Figure 7. The dependence of the dielectric constant of the PZT40/60 thin films annealed at $700^{\circ} \mathrm{C}$ on the bias applied at $100 \mathrm{kHz}$.

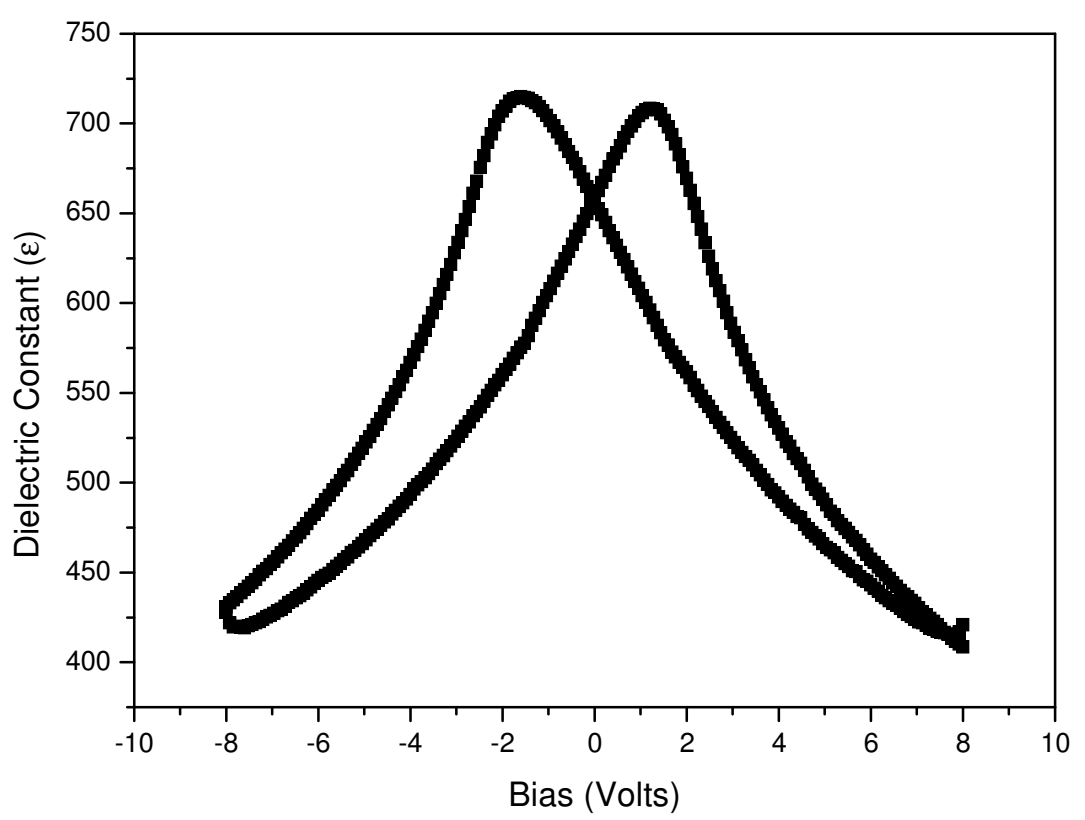


Figure 8. Hysteresis loops for the PZT40/60 thin films measured at different bias applied. (a) 6V; (b) $8 \mathrm{~V}$, and (c) $12 \mathrm{~V}$.

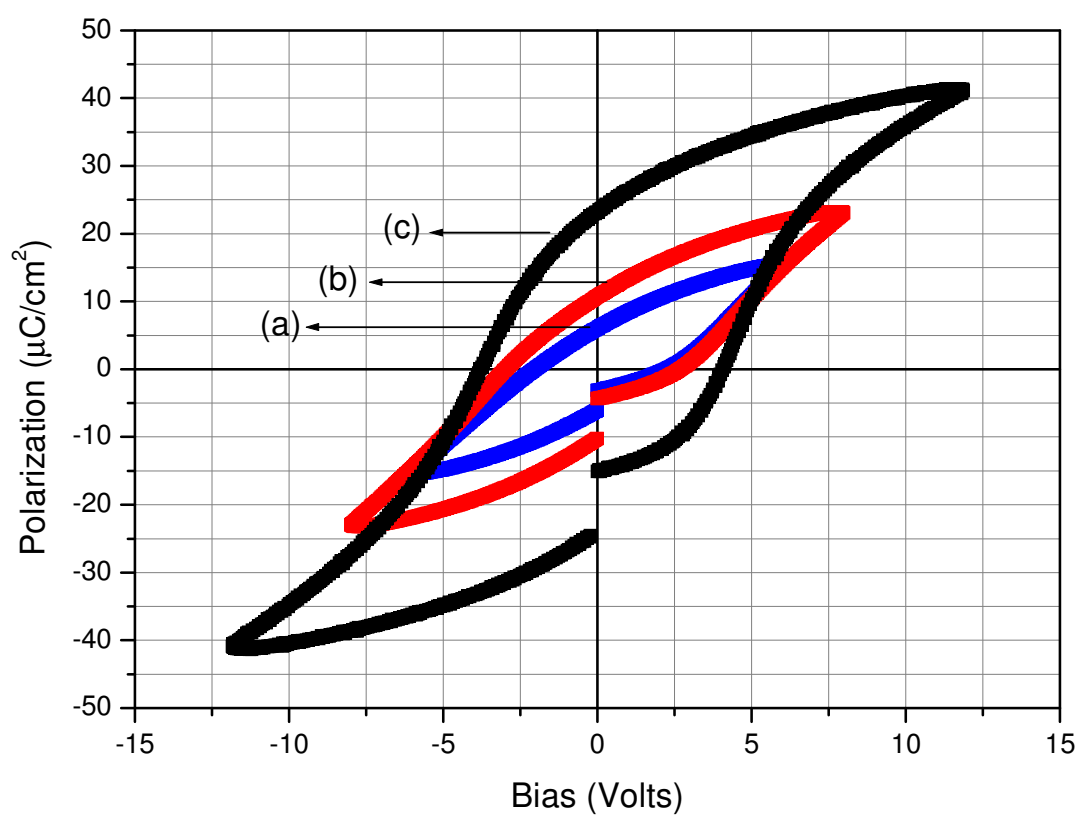


Figure 9. Side view of $\mathrm{PbTiO}_{3}$ slab system, (a) $\mathrm{TiO}_{2}$ terminated nine layers slab and (b) $\mathrm{PbO}$ termination eleven layers. $\mathrm{O}$ atoms are depicted in red and $\mathrm{Ti}$ atoms in blue and $\mathrm{Pb}$ atoms in grey.

(a)

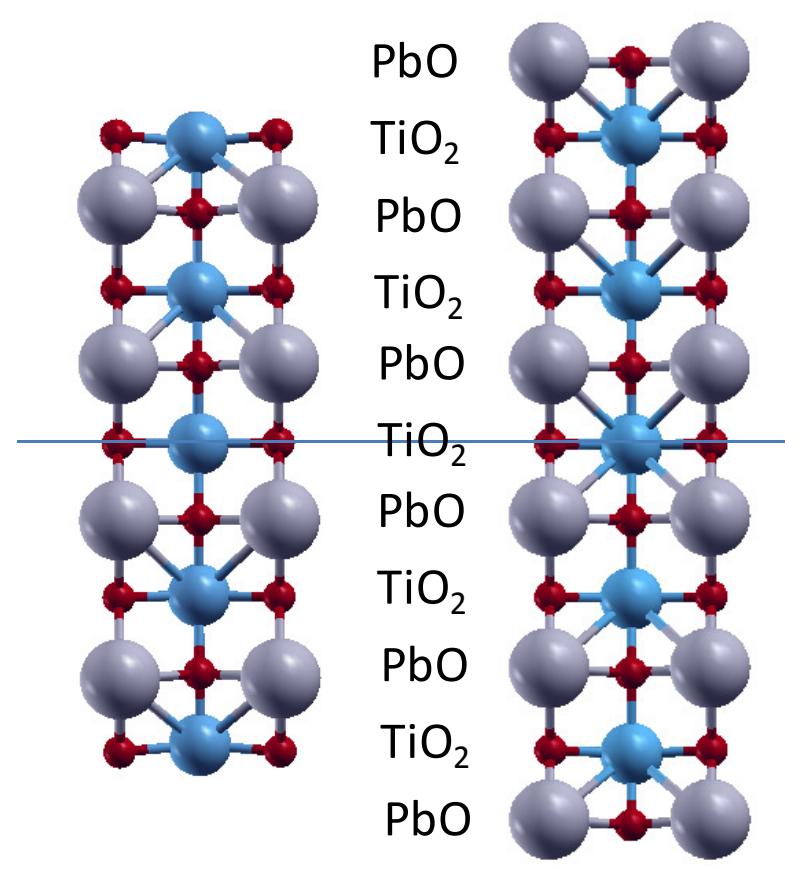

(b) 
Figure 10. Side view of PZT4060 slab system, (a) $\mathrm{ZrO}_{2}$ terminated nine layers slab (b) $\mathrm{PbO}\left(4^{\text {th }} / 8^{\text {th }}\right)$ termination eleven layers and (c) $\mathrm{PbO}\left(2^{\text {nd }} / 10^{\text {th }}\right)$ termination eleven layers. $\mathrm{O}$ atoms are depicted in red, $\mathrm{Ti}$ atoms in blue, $\mathrm{Pb}$ atoms in grey and $\mathrm{Zr}$ atoms in brown. Displacements $\Delta \mathrm{Z}$ between layers are also marked.

(a)

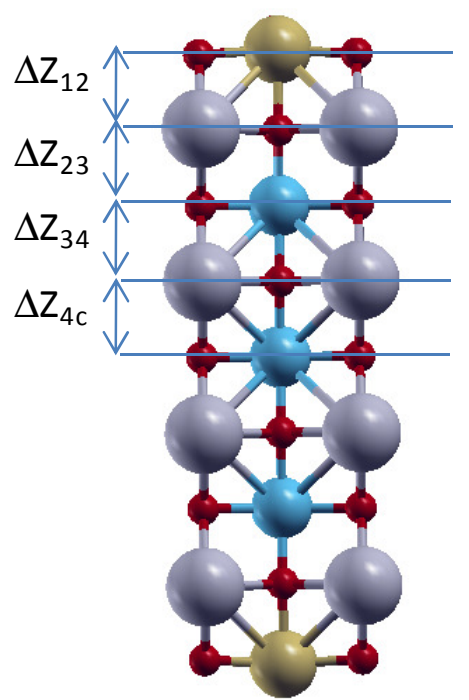

(b)

(c)

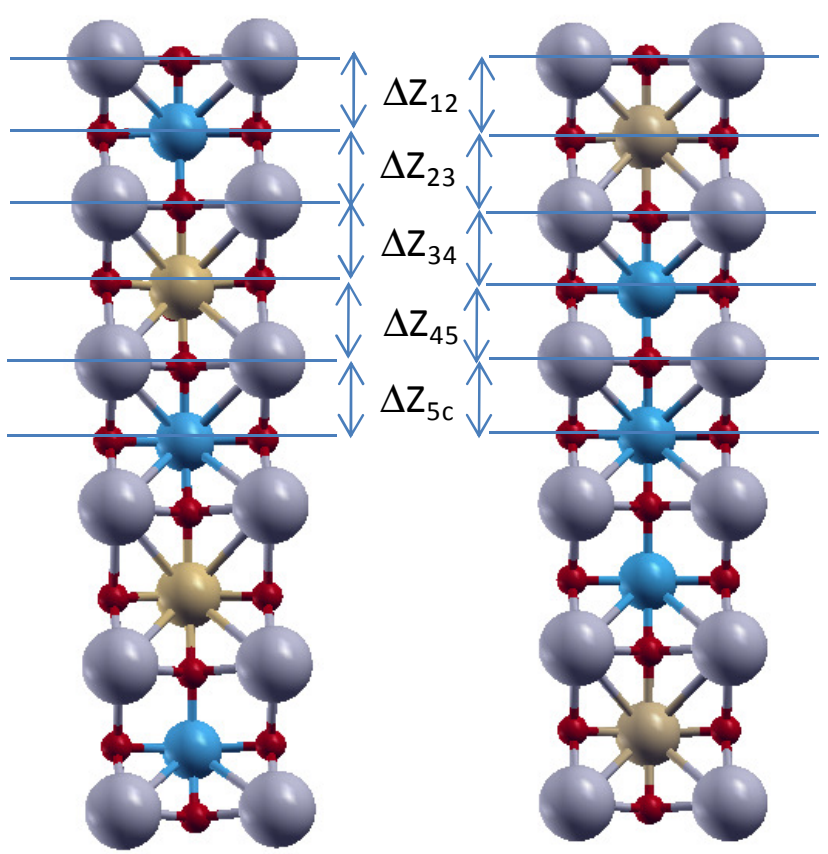


Figure 11. Calculated total and projected $\mathrm{DOS}$ of the $\mathrm{PbTiO}_{3}$ system. (a) $\mathrm{PbO}$ terminated and (b) $\mathrm{TiO}_{2}$ terminated.

a)

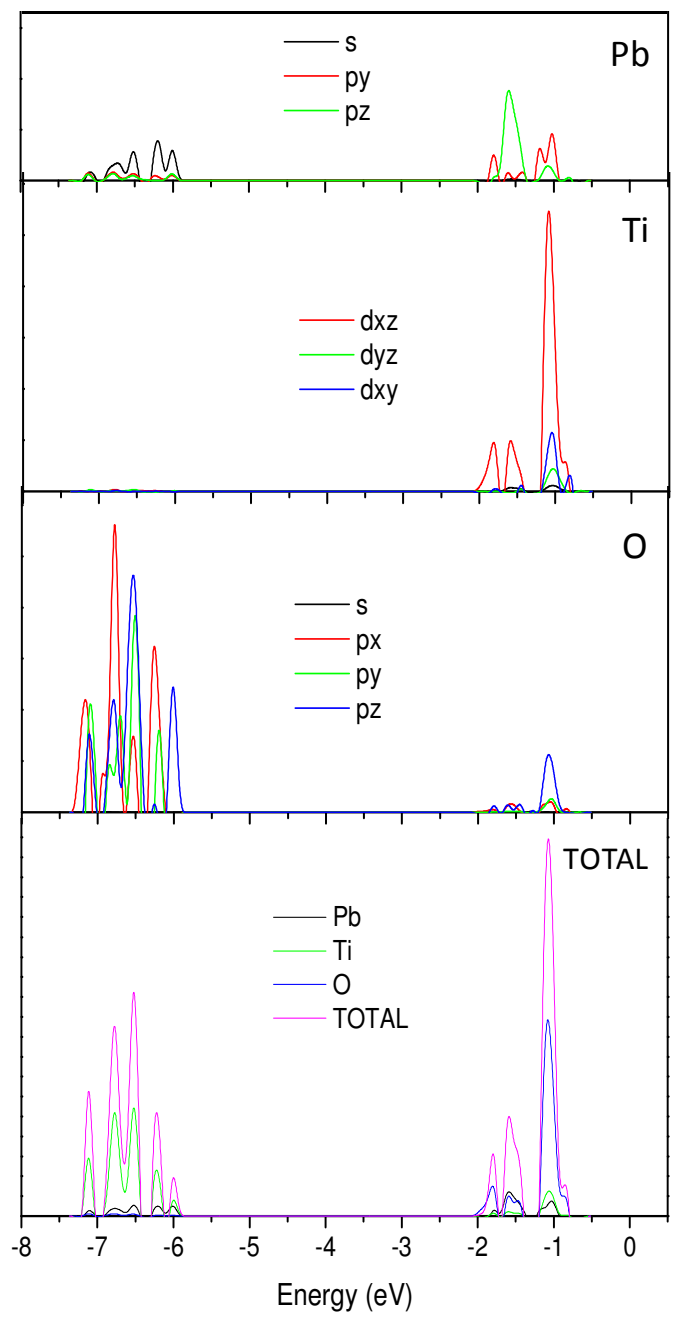

b)

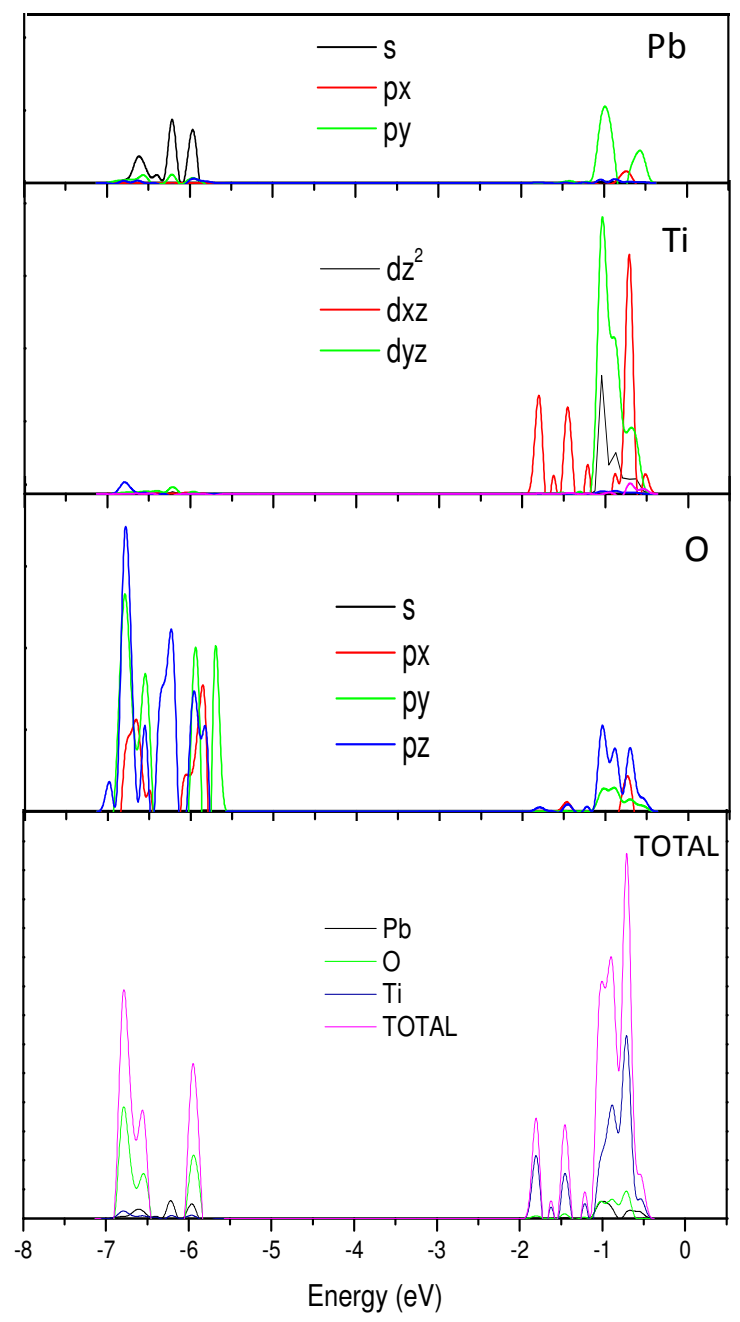


Figure 12. Calculated total and projected DOS of the PZT40/60 system. (a) PbO $\left(4^{\text {th }} / 8^{\text {th }}\right)$ terminated and (b) $\mathrm{ZrO}_{2}$ terminated.

a)

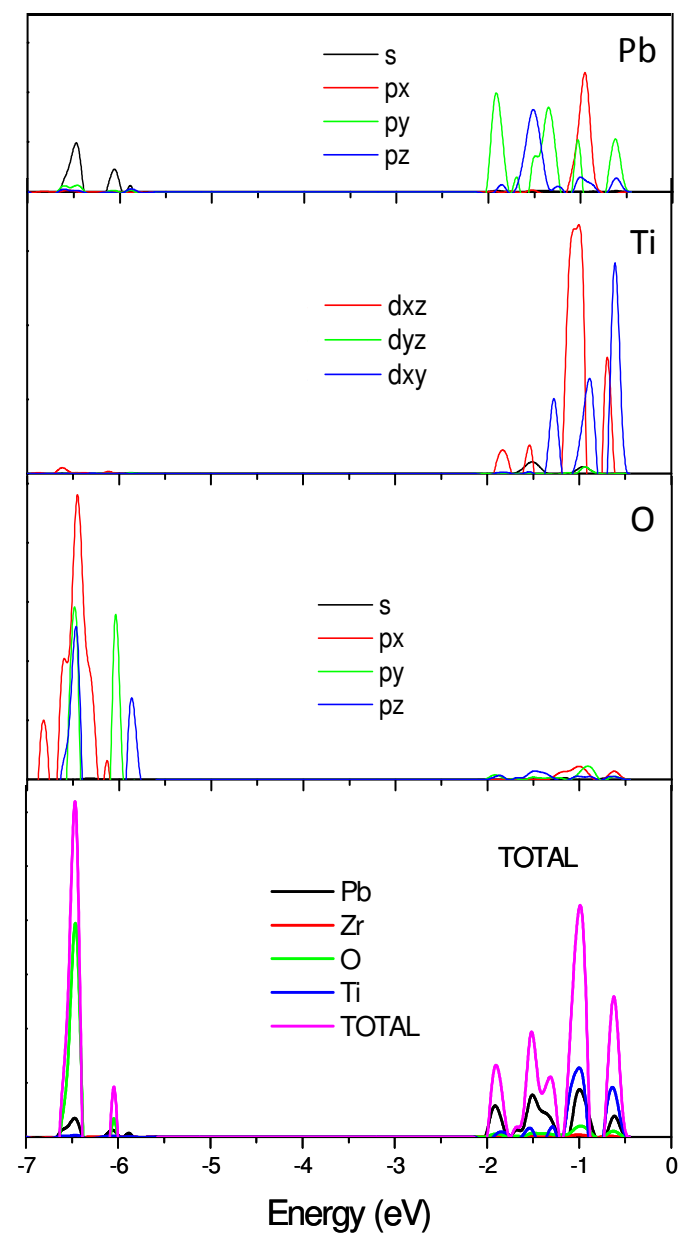

b)

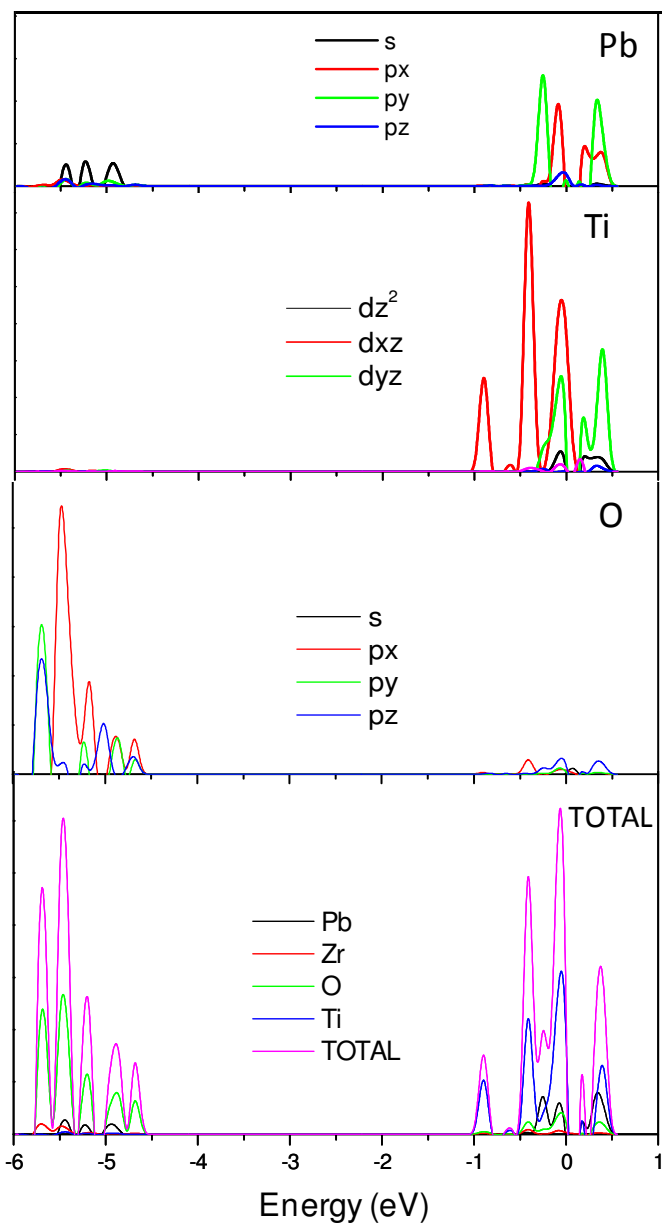


Figure 13. Calculated total and projected DOS of the PZT40/60 system considering $\operatorname{PbO}\left(2^{\text {nd }} / 10^{\text {th }}\right)$ termination.



